\title{
A Review of Electric Vehicles Emissions and its Smart Charging Techniques Influence on Power Distribution Grid
}

\author{
Famous O. Igbinovia*, Ghaeth Fandi, Rateb Mahmoud and Josef Tlustý \\ Department of Electrical Power Engineering,Czech Technical University (CTU) in Prague,Technická 2, 16627 Praha 6 - Dejvice, \\ Prague, Czech Republic
}

Received 11 June 2016; Accepted 10 July 2016

\begin{abstract}
Electric vehicle (EV) technology has lately attained a considerable market share. For sustainability, reliability and efficiency of the electric-power distribution grid, this technology have need of the development and implementation of smart charging techniques. With the fast progress of Electric Vehicles (EVs), large-scale charging demand will tremendously affect existing electric-power distribution grid. Hence, the inevitability for a smart charging regime. This review article briefly talk about the various types of electric vehicles. It discusses the grid, smart grid and their relationship with the electric vehicle. A review case of emissions from EVs have been presented. It outlined some proven smart charging techniques by different authors utilizing diverse tools for the electric vehicle. Thereafter, based on the techniques outlined attempts were made to explain the influence of smart EV battery charging management on the distribution grid. From the foregoing, the authors reached the conclusion that the fair share of coal as electrical energy resource should be minimized in order to reduce carbon dioxide emission from EVs. Furthermore, the various electric vehicle smart charging techniques investigated reveal a promising future for smart charging integrated electric-power distribution grid.
\end{abstract}

Keywords: Electric vehicle, Grid, Smart grid, EV smart charging techniques, Electric vehicles emissions, Electric-power distribution grid

\section{Introduction}

The electric-power system is in the course of transformative modification, the program for minimizing emissions, increment in renewables spread and efficiency in advancement is encouraging the growth of electric vehicles $(\mathrm{EVs})$. An electric vehicle (EV), equally described as an electric drive vehicle, is a vehicle which utilizes one or more electric motors for propulsion. The main types of electric vehicles include: Fuel-cell Electric Vehicles, Hybrid electric vehicles (HEVs), Plug-in Hybrid Electric Vehicles (PHEVs), Extended-Range Electric Vehicles (ER-EVs) and Battery Electric Vehicles (BEVs). For the purpose of this article the term electric vehicle (EV) will be used for BEVs when not referred to in any other way [1-4].

Depending on the kind of electric vehicle, motion perhaps can be made available by wheels or propellers driven by rotary motors, or in the situation of tracked vehicles, by linear motors. Electric vehicles is inclusive of electric cars, electric trains, electric trucks, electric Lorries, electric airplanes, electric boats, electric motorcycles and scooters, and electric spacecraft. With the global energy catastrophe, development in battery technology and increasing significance of energy saving technology, much

*E-mail address: famousigbinovia@yahoo.co.uk ISSN: 1791-2377 @ 2016 Eastern Macedonia and Thrace Institute of Technology. All rights reserved. consideration and preferment is being given to the electric vehicle technology by government and manufacturers alike. Electric vehicles (EVs) is being encouraged as a green replacement to traditional fossil fuel based transportation. There is a global rise of new players in the electricity markets that cater to the growing demand of EVs. [5-8].

Anyhow electric-power is produced, it is transmitted to a vehicle by means of overhead lines, wireless energy transfers like inductive charging, or direct link through an electrical cable. The electric-power may then be stored onboard a vehicle by the use of a battery, flywheel, supercapacitor, or fuel cell. Vehicles working on the principle of combustion normally only obtain their energy from a single or a few sources, typically from fossil fuels. One major merit of the electric vehicle is its capability to recuperate braking energy as electric-power to be restored to the on-board battery, that is regenerative braking or sent back to the grid, Vehicle-to-Grid (V2G). Growing interest over environmental impact of petroleum-based transportation infrastructure, together with the threat of crude-oil price, has led to renewed concern in electric transportation infrastructure. Hence, vehicles that has the possibilities of being powered by renewable energy sources, like pure electric vehicles are attracting global attention [5, 9-10].

Electric Vehicle (EV) charging stations make available energy to charge the batteries of an electric vehicle, these stations are selected localities consisting of external chargers for electric vehicles. Every station is composed of a plug that becomes attached to a vehicle, supplying it with 
electric-power necessary for propulsion. The necessity for electric vehicle charging stations in both industrial and commercial places will grow as plug-in electric vehicles (PEVs) increases. Power system engineers will experience problems during the process of applying the electric vehicle charging stations to their facility electrical power systems [11-14]. With the advancement of electric vehicles, charging infrastructure have also advanced [15].

Recent technological development in electric-power distribution and load management that utilizes information and communications technologies, normally referred to as smart-grids, guarantee to make possible the integration of EVs into electric-power load and to reduce costs. Smart-grid technology allows EV-charging load to be transferred to offpeak time whether grid-to-vehicle $(\mathrm{G} 2 \mathrm{~V})$, thereby bringing down the daily load curve and considerably reducing both generation and network investment requirements. state-ofthe-art metering devices is a necessary constituent, allowing a two-way flow of information and supplying customers and utility authorities with real-time data and permitting customers to cleverly make arrangements for charging. smart charging of an Electric Vehicle is when the charging cycle or revolution can be modified by external occurrences, thereby permitting adaptive charging practices, and making the Electric Vehicle able to integrate into the whole electricpower system in a grid-user-friendly manner. Smart charging should enable the security/reliability of power supply, and at the same time meet the mobility limitations and essentials of the end-user. To attain these objectives in a safe, secure, reliable, sustainable and efficient way, information is required to be exchanged among several stakeholders. smart charging is an operation propelled by both price and control signals. Price signals is when pliable EV loads react to time-of-use, dynamic hourly price of energy, price of maximum instantaneous power demand, and so on. While control signals relates to grid and market circumstances, that is temporary demand for power, which results in an increase in electric-power availability [1, 16].

As the market shares of EVs rises, the electric-power distribution grid will be affected. Similarly, at low market shares, EVs could effortlessly overload local transformers and distort voltage levels. Faced with this circumstances, as power networks were designed to meet consumers demand at all times, the conventional fit-and-forget strategy to power distribution network advancement would insinuate erecting extra lines and transformers. However this strategy may no longer be the most cost-advantageous as it requires high technology adoption costs that might be a burden to the electric-power systems and thereby negatively affecting EVs mass market [1]. This paper is organized as follows: In Section 2 the authors talk about the various types of electric vehicles. Section 3 discusses the grid, smart grid and their relationship with the electric vehicle. Section 4 Illustrates a typical review case of emissions from EVs. Section 5 outlined some proven smart charging techniques for the electric vehicle. While Section 6 attempts to enumerate the influences of smart EV battery charging management on the electric-power distribution grid. And thereafter the paper is concluded.

\section{Types of Electric Vehicles}

2.1 Fuel-cell Electric Vehicles; These vehicles produce electric-power from hydrogen and oxygen. Owing to its efficiency and water-only emissions, it is adjudged to be the leading electric vehicles. Its main component parts is illustrated in figure 1 [1-4, 17-18].

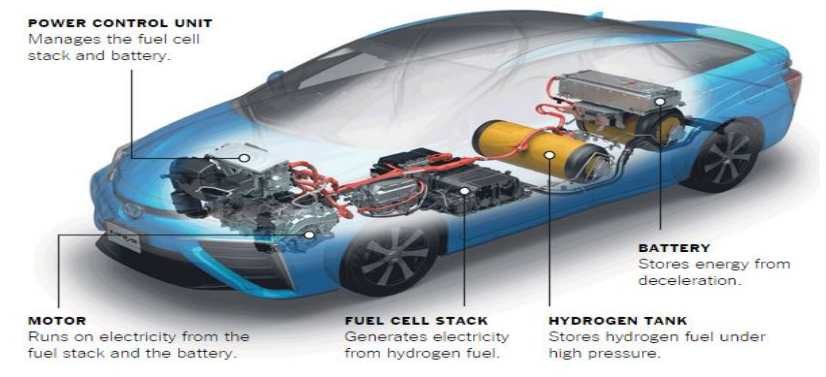

Fig. 1. Main components of a fuel cell electric vehicle [18]

2.2 Hybrid electric vehicles (HEVs); These has two complementary drive structures as can be seen in figure 2: a gasoline engine and fuel tank and an electric motor, battery and controls. The engine and the motor can concurrently turn the transmission, which powers the wheels. HEVs cannot be recharged from the electric-power distribution grid. But its power comes exclusively from gasoline and regenerative braking $[1-4,19]$.

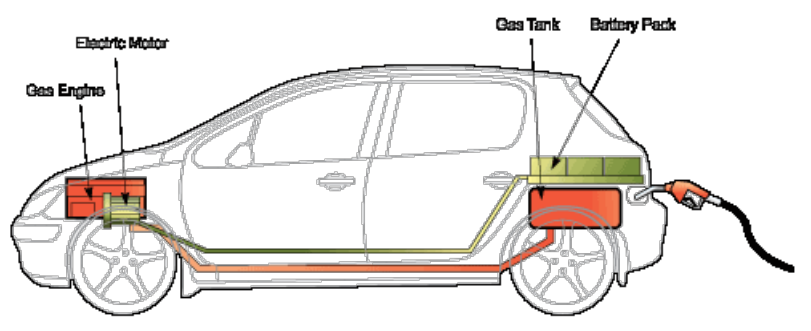

Fig. 2. The structure of an Hybrid electric vehicle [19]

2.3 Plug-in Hybrid Electric Vehicles (PHEVs); These are furnished with internal combustion engine that can recharge the battery and/or to substitute the electric drive train when the battery is low and extra power is needed. Likened to the $\mathrm{HEV}$, it has nevertheless a larger battery-pack and it can be charged exactly from the power grid. The constituent parts of a plug-in hybrid electric vehicle is displayed in figure 3 [1-4. 20].

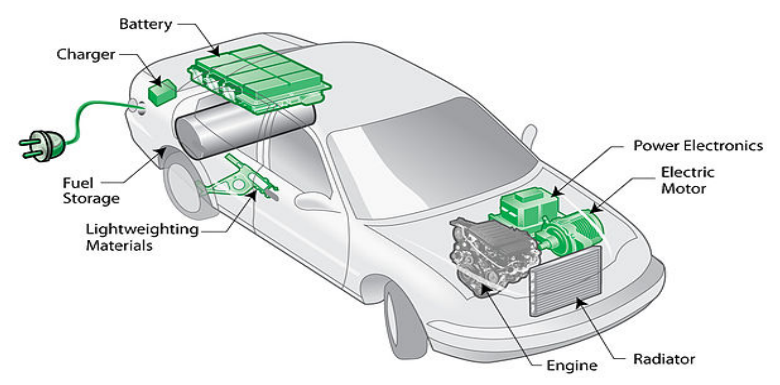

Fig. 3. Constituent parts of a plug-in hybrid electric vehicle [20]

2.4 Extended-Range Electric Vehicles (ER-EVs); Figure 4, represents an ER-EVs, it employs both combustion engines and electric motors, only the electric motor is utilized for propulsion. The combustion engine is utilized to energize a 
generator. The generator subsequently charges the battery, which energizes the motor. ER-EVs equally permit plug-in charging $[1-4,21]$.

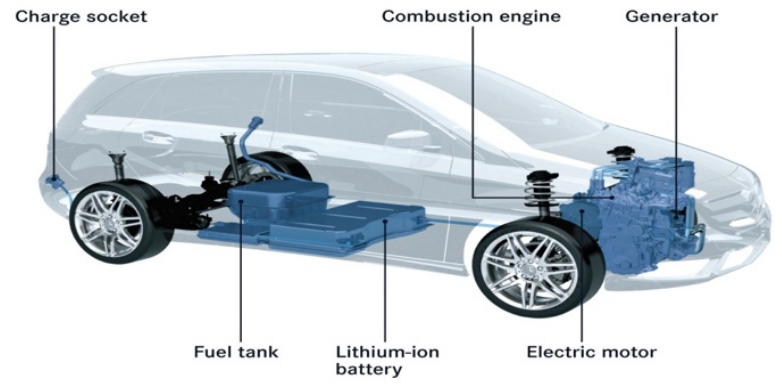

Fig. 4. Key units of an Extended-Range Electric Vehicle [21]

2.5 Battery Electric Vehicles (BEVS); The BEV is all electric, it runs absolutely on a battery and electric drive train, without a traditional internal combustion engine as depicted in figure 5 . These vehicles should be plugged into an external source of electric-power in order to recharge their batteries. Like each and every electric vehicles, BEVs can as well recharge their batteries by means of regenerative braking. This kind of EV needs bigger batteries than the joined electric-petroleum vehicles [1-4, 22-23].

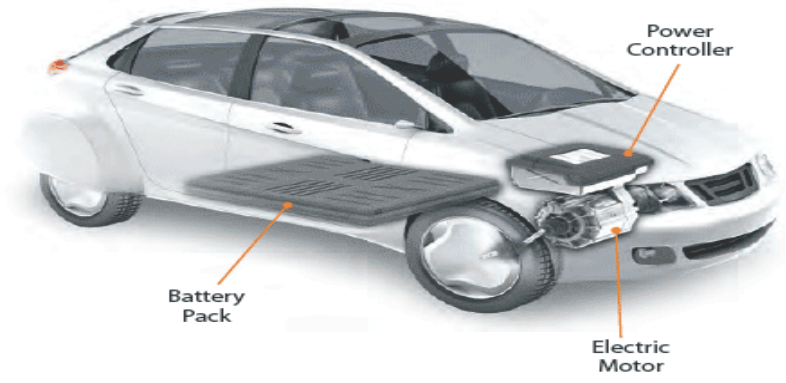

Fig. 5. Essential items of a battery electric vehicle [23]

\section{The Grid, Smart Grid and their relationship with the Electric Vehicle}

The Grid is comprise of interconnected electrical power systems that convey electric-power from the plants where it is generated to the end-user. The grid includes wires, substations, transformers, switches and lots more. It applies to the electric-power grid, an interconnected system of transmission lines, substations, transformers and much more that deliver electric-power from the power plant to homes or businesses. Despite the fact that the electric-power grid is regarded as an engineering wonder, it is being stretched to its mix or patchwork capacity. For further advancement, we require a new type of electric-power grid, that is built to handle digital and computerized equipment and on which technology depends on. An electric-power grid that can automate and manage the increasing complexity and present needs of the electric-power systems [24-25]. A Smart Grid is an advanced grid system that manages or controls electricpower demand in a sustainable, reliable and economic way, it is built on modern infrastructure and adjusted to ease the integration of all connected. It can be referred to as the digital technology that permits two-way communication connecting utility authorities and its customers, and sensing on the electric-power lines. Like the Internet, the Smart Grid is composed of controls, computers, automation, new technologies and equipment functioning simultaneously, but in the case of the Smart Grid, these technologies will work with the electric-power grid to react digitally to fast adjusting electric-power demand. The advantages related with the Smart Grid include: Better efficiency in the transmission of electric-power; Faster restoration of electricpower in the wake of power disruption; Minimized operation and management costs for utility authorities, and eventual reduction of electric-power costs for end-users; Lowering electric-power peak demand, which helps to reduce electricity rates; A growth in the integration of large-scale renewable energy generation to the electric-power systems; Improved integration of customer-owned electric-power generating systems, inclusive of renewable energy systems; And enhancement of the security of electric-power system. A vivid description of the smart grid is shown in figure 6 , [24-27].

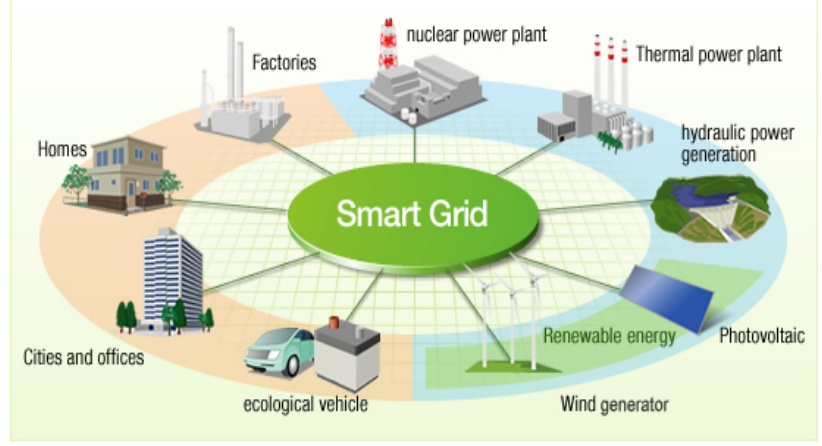

Fig. 6. The Smart Grid [27]

The present electric-power grid all over the globe, does not provide any notable storage capacity. This imply that every kilowatt-hour of electric-power utilized must be produced instantaneously at the very same moment. Meaning that for every unit of electric-power produced by utility authorities, it need to be matched with the exact unit of electric-power demanded. Hence, there should be a balance between the unit of electric-power produced by utilities and the unit of electric-power demanded by customers or end-users. This necessity is likely the greatest challenge towards the actualization of a sustainable electricpower supply centred on renewable energy sources, like photovoltaic panels and wind power plants. Since their electric-power output varies with time, it is commonly not reliably predicted and most times their output differs considerably from the actual electric-power demand. Specifically, lack of availability of electric-power from renewable energy sources during lengthened calm and cloudy times present the greatest obstacle. To provide sufficient electric-power at such times, large fleet of traditional power plants has to be on standby mode, prepared to take over when renewable energy sources can no longer satisfy customers demand. Another option is to build gigantic facilities, like the pumped storage or batteries that will be able to store electric-power for a longer duration of time. Pumped storage and battery technology requires costly hardware facilities and maintenance expenditures when compared to traditional power plants. Smart grids and demand control techniques make available a less costly and better reasonable hardware wide-ranging options for the smart charging of electric vehicles. This is realized by relaxing the connection between electric-power production and demand, hinge on developing a technique such that electric-power demand can be controlled to match with 
variations in electric-power supply. Achieving this, entails shifting less urgent electric-power consumption out of times of peak demand onto periods of surplus electric-power production. The introduction of smart charging technologies into several spheres of human endeavor is the most positive way out to realize a reliable integration of renewable energy sources onto the electric-power production or generation mix. In the long run, an increase in the installation of smart charging technology will reduce the numbers of needed standby power plants and save related construction and operational costs [28-31]. There is a growing interest in incorporating the demand control strategy into electric vehicles. This is accomplished by means of the use of power line communication and electricity market pricing mechanisms [28, 32-37].

\section{A Typical Review Case of Emissions from Electric Vehicles}

Figure 7, shows a comparison between the emissions from petrol cars and electric cars by utilizing electric-power generated from traditional power stations. Generally, there are less emissions from electric cars. Eco-Points rating shows that electric cars would yield only a third of the pollution that petrol cars make, particulate matter generated is 3.6 times extra than gasoline cars in places depending on traditional natural resources for electric-power supply. Nitrogen oxides $\left(\mathrm{NO}_{\mathrm{x}}\right)$ emission from petrol cars is also very high as compared to that of electric cars [8]

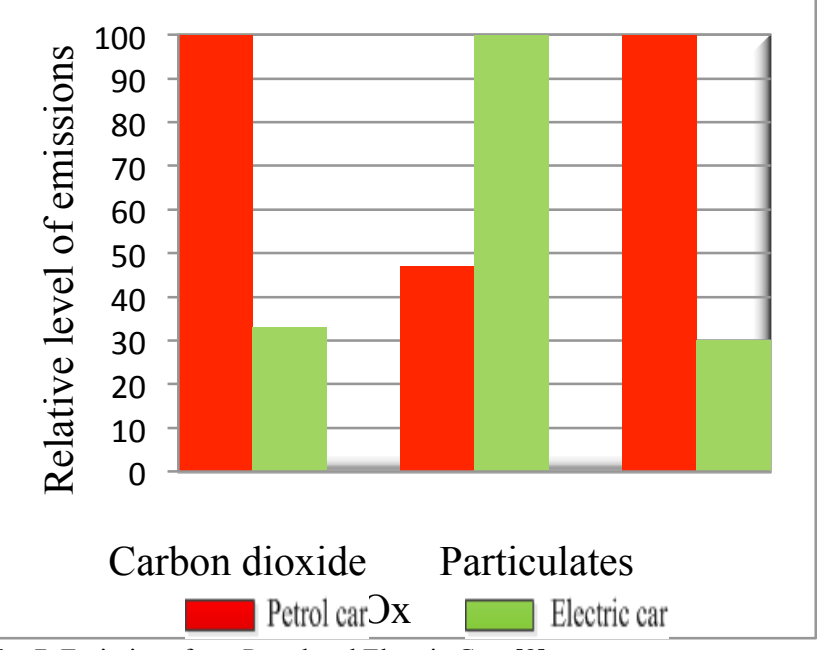

Fig. 7. Emissions from Petrol and Electric Cars [8]

Electric vehicles are distinct from fossil fuel-energized vehicles in that they can get energy from diverse sources, inclusive of fossil fuels, nuclear power, and renewable sources like tidal power, solar power, and wind power or whichever mix of those shown in figure 8 (a) and (b), it also shows annual $\mathrm{CO}_{2}$ emission per vehicle in two different places (Locations A, figure 8 (a) and Location $\mathrm{B}$, figure 8 (b)), since the breakdown of energy source is unique from one place to another, an EV will be greener in some places than others. For instance, a place that utilizes very small coal, the EV's emissions are far less than that of a gas car. In heavy coal locations or places, EVs create a lot extra $\mathrm{CO}_{2}$ emissions, but quiet less than a gas car [9]. In figure 8 (a) and (b), HEV = traditional hybrid car, PHEV = plug-in hybrid car, and $\mathrm{EV}=$ battery electric car.

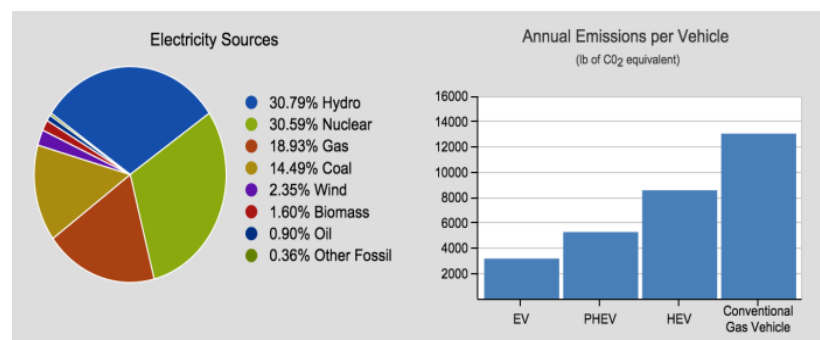

Fig. 8 (a), Location A.

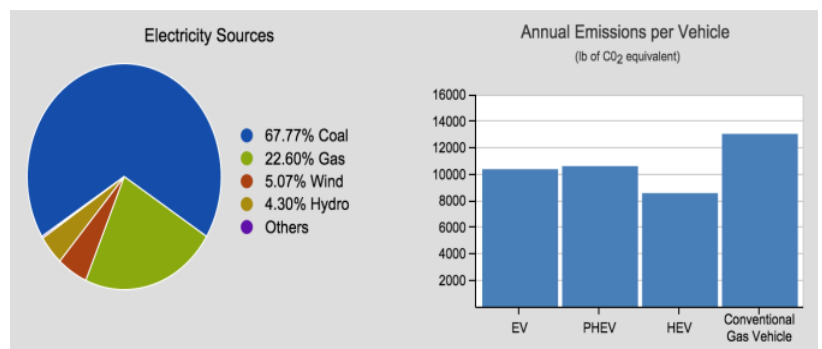

Fig. 8 (b) Location B.

Fig. 8. A breakdown of generated energy sources and annual emission per vehicle of $\mathrm{CO}_{2}$ at two different places, Location A and B [9]

\section{Electric vehicles smart charging techniques}

Smart charging pertain to a controlled charging technique that optimizes the utilization of the electric-power grid and the obtainable electric-power to curtail extra investments in the electric-power system and ease the integration of renewable energy sources. It is the conveying of information and services between an electric vehicle and Smart grid stakeholders, in order to provide and sustain a safe, reliable and user friendly charging infrastructure. The control technique can be facilitated by the electric-power grid through the charging point or by the vehicle itself, and putting into consideration the communication system with the electric-power grid permitting the charging operation to assume real electric-power grid abilities. Price or control signals can be conveyed by means of Information and communications technology (ICT) infrastructure, such as intelligent metering system, in order to permit intelligent charging algorithms to take generation or production and electric-power grid limitations into account and to permit customers to profit from price opportunities. [38-39]. Some of the smart charging techniques enumerated in this article are real life analysis, while others are simulated scenarios which are appropriate for practical implementation, these include:

Optimal Charging Scheduling using Heuristic Algorithms; This is an optimization algorithm to synchronize the charging of electric vehicles developed and implemented utilizing a Genetic Algorithm (GA), where thermal line boundaries, the load on transformers, voltage boundaries and parking availability patterns are taken into account or provided for to create an optimal load pattern for electric vehicle charging-based reliability [40].

WINSmartEV $V^{\mathrm{TM}}$ smart electric vehicle charging system: This is a demonstration of an electric vehicle charging system that is presently in operation. It is a software and network based electric vehicle charging system designed and built on the concepts of intelligent charge scheduling, multiplexing (that is connecting multiple vehicles to each circuit) and flexibility [41]. 
Comprehensive smart charging system: It is a unique system that leverages mobile and Radio-Frequency IDentification (RFID) technologies, aggregation middleware, and an aggregated charge scheduling algorithm. [42].

Smart Real-time Coordination System (SRTCS): This is an innovative online coordination technique for the charging of plug-in electric vehicles (PEVs) in smart distribution systems, the unconventional prediction unit can predict future or anticipated PEVs power demand using an innovative two-stage optimization unit that ensures effective charging coordination. It optimally charges PEVs in order to maximize owners' satisfaction and minimize electric-power systems operating costs without violating power system constraints [43].

Strategic charging method: This is a PHEVs' charging scheduling programs intended for optimizing customers charging cost by bearing in mind generation ability constraint and dynamic electricity price in different time slots of day. It utilizes stochastic model for start time of charging and duration in the optimization algorithm, thus making this technique a practical tool for modeling vehicle owners' charging behavior with the motive of peak load shaving. it regards PHEV owners to be price anticipator implying that they are willing to cut-down their cost of charging with regards to electric-power prices in each time slot. Also, PHEV charging is perceived as a game among car owners, the intention of which is to curtail car owners' cost of charging. It is based on probabilistic model of customers' behavior which is more correct in practical implementations [44].

\section{Influence of Smart EV Battery Charging Management on Distribution Grid}

The influence of electric vehicles on the distribution grid can be decided by EVs smart charging techniques. The influence they will have on the distribution grid have been measured and calculated by different authors in various places utilizing diverse tools that vary from analytical techniques to simulations and beyond [45]. For the purpose of this work, the authors have enumerated the influence of the various smart charging techniques outlined in Section 3 on the electric-power distribution grid. These are as follows:

It reduces power losses, voltage deviations and prevents the aging of power system elements [40, 42, 46-48]: Optimal Charging Scheduling using Heuristic Algorithms have been used in low-voltage residential system. Here, EVs could be viewed as loads or generators hinging on the indispensability of the Distribution System Operator (DSO). This provides benefits to DSOs with regards to evaluating the load demand of electric-power systems, peak load shaving, flattening load profile and reducing transformer aging. Furthermore, it is a Vehicle to Grid (V2G) technology which can be utilized to address distributed energy resource generation oscillations and qualifies EVs to be regarded as new generator in the electric-power generation portfolio [40].

It maximizes the use of available grid resources, thereby enhancing grid stability [41, 43, 49]: The WINSmartEV TM smart electric vehicle charging system has the capability to optimally schedule charging in order to securely maximize the utilization of accessible grid resources for charging EVs and thereby maximizing the number of EVs that can be linked to the grid while enhancing grid stability [41].

It saves cost by capitalizing on off-peak charging benefits, and generate revenue for parking garage operator [40, 42, 46, 47]: The comprehensive smart charging system brings about costs savings, peak load reduction or minimizing, ease electric-power grid load during peak hours, capitalize on off-peak charging benefits, and generate revenue for parking garage operator. It is well suited for implementation in an enterprise environment where huge numbers of EVs could be aggregated to substantially influence peak load alleviation and act as a notable energy resource [42].

It provides robustness, immunity to extreme load conditions, and an acceptable computation time for smart electric-power distribution systems [43, 50]: The Smart Real-time Coordination System (SRTCS) provides robustness, immunity to high risk load situations, and an acceptable computation time for smart electric-power distribution system, It as well allows better utilization of electric-power system resources [43].

It decrease peak load growth and customer electricity bill cost [40, 44, 46-47]: Strategic charging technique is an algorithm that can be utilized by utility authorities to persuade customers to use their smart chargers by moving charging to times that electric-power provision is cheap. It brings about near-optimum scheduling with high convergence speed, acceptable distribution of load for varying penetration levels of PHEVs, and at the same time, putting into consideration the probabilistic behavior of customers. This reveals the benefits and potentials of the algorithm for developing load management strategies in power markets [44].

\section{Conclusion}

The authors of this review article have been able to outline smart charging techniques, based on measured and calculated results by different authors in various places of the globe utilizing diverse tools to analyze real-life and simulated scenarios. All the techniques discussed in this paper have great influence on the electric-power distribution grid as outlined in Section 6. This article has shown that to reduce carbon dioxide emission from EVs, the fair share of coal as electrical energy resource should be discouraged or drastically minimized. Future research work should be focused on practical or real-life implementation of simulated techniques outlined in this article. Also, conscious effort should be made towards extending these smart charging techniques to other electrical devices or equipment's which offer flexibility in their utilization and power consumption. And more work should be done on the reduction of particulate emission in electric vehicles, when using electricpower generated from traditional power sources.

\section{Acknowledgement}

The financial support of the Grant Agency of the Czech Technical University in Prague (grant No. SGS14/188/OHK3/3T/13) is highly acknowledged. 


\section{References}

1. EURELECTRIC, Smart Charging: steering the charge, driving the change, A EURELECTRIC paper, [Online]. Available from: http://www.eurelectric.org (2015).

2. CAA, Types of Electric Vehicles. [Online]. Available from: http://electricvehicles.caa.ca

3. L. F. Hexeberg, Strategies for Smart Charging of Electric Vehicles. Master Thesis, Norwegian University of Science and Technology, Trondheim, Norway, (2014).

4. C. Edison, Electric Vehicles. [Online]. Available from: http://www.coned.com

5. ElectricVehicleNews.com, Electric Vehicles Definition, [Online]. Available from: http://electricvehiclesnews.com

6. Y. Huang, J. Liu, X. Shen, T. Dai, The Interaction between the LargeScale EVs and the Power Grid, Smart Grid and Renewable Energy, Scientific Research, pp. 137-143 (2013).

7. J. Hoog, D. A. Thomas, V. Muenzel, D. C. Jayasuriya, Tansu Alpcan, M. Brazil, and I. Mareels, Electric Vehicle Charging and Grid Constraints: Comparing Distributed and Centralized Approaches, Conference: IEEE Power and Energy Society General Meeting, At Vancouver, Canada, (2013).

8. Sustainability-ed, Are electric cars sustainable? [Online]. Available from: http://www.sustainability-ed.org.uk

9. T. Urban, How Tesla Will Change The World, [Online]. Available from:http://waitbutwhy.com (2015)

10. J. Hu, S. You, C. Si, M. Lind, and J. Østergaard, Optimization and control method for smart charging of EVs facilitated by Fleet operator: Review and classification, International Journal of Distributed Energy Resources and Smart Grids, Technology \& Science Publishers, Kassel, Germany, Volume 10 Number 1, pp. 383 - 397 (2013).

11. APQI, So What is Power Quality, Asia Power Quality Initiative, [Online]. Available from: http://www.apqi.org

12. OpenEI, Plug-in Electric Vehicle Charging Station, [Online]. Available from: http://en.openei.org

13. AV, Electric Vehicle (EV) Charging Stations, AeroVironment Glossary, [Online]. Available from: http://www.avinc.com

14. G. H. Fox, Getting Ready for Electric Vehicle Charging Stations, [Online]. Available from: http://apps.geindustrial.com

15. Y. Fan, C. Guo, W. Qi, and Z. Tang, Impact Analysis of Off-board Charger to Power Quality, Energy and Power Engineering, Scientific Research, 5, pp. 1337-1343, (2013).

16. T. Morgan, Smart grids and electric vehicles: Made for each other? International Transport Forum, OECD. Discussion Paper No. 201202. (2012).

17. B. Stevens, Are Hydrogen Fuel Cells Vehicles Dead On Arrival? Barry on energy. https://barryonenergy.wordpress.com (2014).

18. M. Kumalo, Can You Change The World By Driving A Hydrogen Car? https://www.linkedin.com/pulse/end-iceage-maurice-kumalo (2015).

19. http://www.mto.gov.on.ca

20. E. Dickinson, Do Hybrid and Electric Vehicles Have the Pulling Power? COMSOL Blog. https://www.comsol.com (2015).

21. Zero emission Motoring, Mercedes-Benz Concept B-Class E-CELL Plus, http://www.zemotoring.com (2011).

22. AE News, Electric Cars, http://www.alternative-energy-news.info

23. A. Mahmassani, Electric-Drive Vehicles, Union of Concerned Scientists. http://www.ucsusa.org (2012).

24. Energy.gov, Smart Grid [Online]. Available from: http://energy.gov

25. Smartgrid.gov, What is the Smart Grid? [Online]. Available from: https://www.smartgrid.gov

26. ABB, What is a smart grid? [Online]. Available from: http://new.abb.com

27. Hitachi, Smart Grid. [Online]. Available from: http://www.hitachi.com

28. S. Hild, S. Leavey, C. Gräf, and B. Sorazu, Smart Charging Technologies for Portable Electronic Devices. Cornell University Library, (2013).

29. J. A. Short, D. G. Infield, and L. L. Freris, Stabilization of Grid Frequency Through Dynamic Demand Control, IEEE Transactions on Power Systems Vol. 22, No. 3, Page 1284, (2007).

30. National Grid. Frequency Control by Demand Management (FCDM). http://www.nationalgrid.com (2011).

31. G. Strbac, Demand side management: Benefits and challenges, Energy Policy Vol. 36, pp. 4419-4426 (2008).
32. F. A. Amoroso and G. Cappuccino, Impact of charging efficiency variations on the effectiveness of variable-rate-based charging strategies for electric vehicles, Journal of Power Sources, (2011).

33. E. Sortomme and M. El-Sharkawi, Optimal Charging Strategies for Unidirectional Vehicle-to-Grid, IEEE Trans. On smart grid, Vol 2, 1, (2011).

34. N. Rotering and M. Ilic, Optimal Charge Control of Plug-In Hybrid Electric Vehicles in Deregulated Electricity Markets, IEEE Trans. On Power System, Vol 26, 3, (2011).

35. C. Huang, J. T. Boys, G. A. Covic, J. R. Lee, R. V. Stebbing, Implementation and Evaluation of an IPT battery charging system in assisting Grid Frequency Stabilisation through Dynamic Demand Control, IEEE Vehicle Power and Propulsion Conference, pp. 1 - 6, (2010).

36. M. Ifland, N. Exner, and D. Westermann, Appliance of Direct and Indirect Demand Side Management, IEEE, Energytech, Cleveland, OH, pp. 1-6, (2011).

37. S. Bashash, S. J. Moura, J. C. Forman, H. K. Fathy, Plug-in hybrid electric vehicle charge pattern optimization for energy cost and battery longevity, Journal of Power Sources, Volume 196, Issue 1, pp. 541-549 (2011).

38. EURELECTRIC, European electricity industry views on charging Electric Vehicles. A EURELECTRIC position paper D/2011/12.205/6, [Online]. Available from: http://www.eurelectric.org (2011).

39. Focus Group on European Electro-Mobility, Smart Charging of Electric Vehicles. E-mobility Coordination Group (EM-CG), [Online]. Available from: http://www.emic-bg.org (2012).

40. M. Alonso, H. Amaris, J. G. Germain and J. M. Galan, Optimal Charging Scheduling of Electric Vehicles in Smart Grids by Heuristic Algorithms. Energies, 7, 2449-2475, (2014).

41. J. Chynoweth, C. Chung, C. Qiu, P. Chu, R. Gadh, Smart Electric Vehicle Charging Infrastructure Overview, IEEE PES Innovative Smart Grid Technologies (ISGT) Conference, Washington, DC, USA, pp. $1-5,(2014)$.

42. S. Mal, A. Chattopadhyay, A. Yang, R. Gadh, Electric vehicle smart charging and vehicle-to-grid operation. International Journal of Parallel, Emergent and Distributed Systems, Vol. 27, no. 3, (2012).

43. M. F. Shaaban, M. Ismail, E. F. El-Saadany, W. Zhuang, Real-Time PEV Charging/Discharging Coordination in Smart Distribution Systems. IEEE Transactions on Smart Grid, Publisher: IEEE, Volume 5. Issue 4, pp. 1797-1807, (2014).

44. A. Sheikhi, S. Bahrami, A. M. Ranjbar, H. Oraee, Strategic charging method for plugged in hybrid electric vehicles in smart grids; a game theoretic approach. International Journal of Electrical Power and Energy Systems. Elsevier, Volume 53, pp. 499-506, (2013).

45. R. C. Green II, L. Wang, M. Alam, The impact of plug-in hybrid electric vehicles on distribution networks: A review and outlook. Renewable and Sustainable Energy Reviews, Elsevier, Volume 15, Issue 1, pp. 544-553, (2011).

46. K. Clement-Nyns, E. Haesen, J. Driesen, The Impact of Charging Plug-In Hybrid Electric Vehicles on a Residential Distribution Grid. IEEE Transactions on Power Systems, Volume:25 , Issue: 1, pp. $371-380,(2010)$.

47. K. Mets, T. Verschueren, W. Haerick, C. Develder and F. D. Turck, Optimizing Smart Energy Control Strategies for Plug-In Hybrid Electric Vehicle Charging, Network Operations and Management Symposium Workshops (NOMS Wksps), 2010 IEEE/IFIP, Osaka, pp. $293-299,(2010)$.

48. S. Deilami, A. S. Masoum, P. S. Moses, and M. A. S. Masoum, Real-Time Coordination of Plug-In Electric Vehicle Charging in Smart Grids to Minimize Power Losses and Improve Voltage Profile, IEEE Transactions on Smart Grid, pp. 456 - 467, (2011).

49. J. A. P. Lopes, F. J. Soares, and P. M. R. Almeida, Integration of Electric Vehicles in the Electric Power System, Proceedings of the IEEE, Volume:99, Issue: 1, pp. 168 - 183, (2011).

50. E. Sortomme, M. M. Hindi, S. D. J. MacPherson, and S. S. Venkata, Coordinated Charging of Plug-In Hybrid Electric Vehicles to Minimize Distribution System Losses, IEEE Transactions on Smart Grid, Volume 2 , Issue: 1, pp. 198 - 205, (2011). 